EVS24

Stavanger, Norway, May 13-16, 2009

\title{
Development of a Series Hybrid Electric Vehicle as Low-Floor City Transit Bus
}

\author{
Uk-Don Choi ${ }^{1}$, Se-Jin $\mathrm{Oh}^{2}$, Chang-Hee Lee ${ }^{3}$, Se-Hyun Lee ${ }^{4}$ \\ ${ }^{1,3,4}$ Hyundai Heavy Industries Co., Ltd. Electro-Mechanical Research Institute, \\ 102-18 Mabuk-dong, Giheung-gu, Yongin-si, Gyeonggi-do 446-716, Korea, udchoi@hhi.co.kr \\ ${ }^{2}$ Daewoo Bus Corporation, 1085-1, Banyeo-dong, Haeundae-gu, Busan,612-060, Korea, phoebus@daewoobus.co.kr
}

\begin{abstract}
In this paper, simulation and test results of a low floor Series Hybrid Electric Vehicle running in BUSAN city driving mode are presented. Hyundai Heavy Industries Company and Daewoo Bus Corporation have jointly developed a prototype Series Hybrid Electric Bus (SHEB) to evaluate vehicle performance together with fuel economy as a part of feasibility study on hybrid bus operation. It is found that the fuel efficiency of SHEB is $22 \%$ higher than that of a conventional internal combustion engine bus and our GENSET control method is quite effective in maintaining that battery's State of Charge (SOC) during bus driving.
\end{abstract}

Keywords: vehicle performance, SHEB, generator, fuel economy, series HEV

\section{Introduction}

Series Hybrid Electric Vehicle is intended for reducing exhaust emission and improving fuel economy during driving in a trafficcongested city. The method to improve the fuel efficiency is to use the larger energy storage system. A large capacity energy storage system (ESS) and an optimal electric power generator (GENSET) are used in the SHEV. These devices substantially have some weakness since it can take large portion of the vehicle price. In this study, the vehicle to minimize the capacity of the energy storage system together with the GENSET for the flat and even city road is developed with similar level of performance to conventional one. The performance test was conducted with the road running mode in downtown of BUSAN city, which has proven that the SHEV has the fuel saving effect of $22 \%$ compared to the ordinary vehicles. This result is obtained considering the practical road running condition rather than the chassis dynamometer testing condition generally used in the test. Only the one-step planetary reduction gear with high efficiency which is directly connected to the electric motor without use of transmission is used in the test. The monitoring system is applied as a substitute for the existing meter cluster. The bus was exhibited in Seoul Motor Show held in 2007.

\section{System configuration}

The SHEV consists of a propulsion motor for driving the wheels, a battery as an energy storage system to undertake the power supply of vehicle, and the GENSET that plays roles in power supply of the motor and battery recharging, and auxiliary devices to drive the air compressor and others to control the power steering and brake. In addition, it 
also has the monitoring system that may monitor the vehicle condition and replace various meters. Figure 1 shows system structure of the SHEB. As shown in Figure 1 and Figure 3, the propulsion motor does not use the transmission but the reduction gear of the planetary type. The output of the motor with reduction gear is connected to the differential gear of the vehicle through the drive shaft. The GENSET is directly connected to the engine as shown in Figure 1. Driving of a propulsion motor and an auxiliary motor is undertaken by an inverter, and the unit for the propulsion motor control is referred to as MCU (Motor Control Unit) and the GENSET control unit is referred to as GCU (Generator Control Unit). The dotted line as shown in Figure 1 is for the inverter for propulsion motor drive and the inverter for the generator and auxiliary motor.

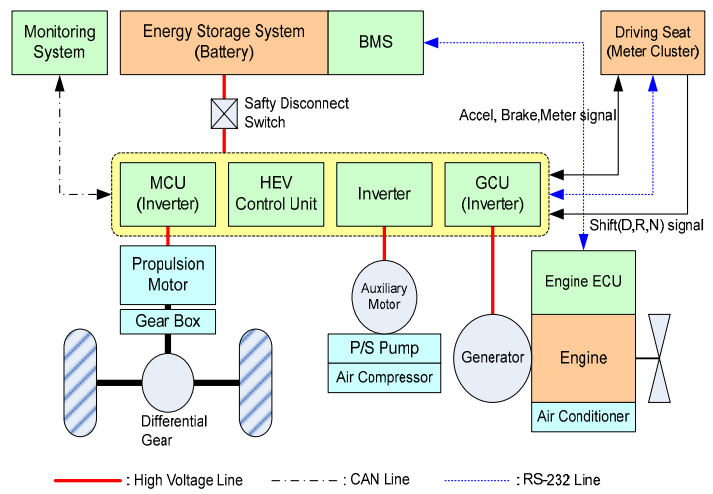

Figure 1: System Architecture of the SHEB

Target performance of the developed SHEB is shown in Table 1. The maximum speed of vehicle, acceleration and fuel efficiency is better than those of an Internal Combustion Engine Bus (ICEB) but the SHEB's gradeability is $75 \%$ of ICEB's since ICEB with a five-speed gear has more torque than SHEB.

Table 1: Target Performance

\begin{tabular}{|c|c|c|}
\hline & ICEB & SHEB \\
\hline 0-60km/h Acceleration (sec) & 16.4 & 13 \\
\hline Fuel consumption (km/liter) & 2.1 & 2.58 \\
\hline Fuel improvement (\%) & - & Over 20 \\
\hline Gradeability (\%) & 33 & 25 \\
\hline Maximum speed (km/h) & 102 & Above 100 \\
\hline Engine displacement (cc) & 11,051 & 3,900 \\
\hline Battery (V/Ah) & - & $336 / 53.8$ \\
\hline Vehicle weight $(\mathrm{kg})$ & 1,570 & 1,550 \\
\hline
\end{tabular}

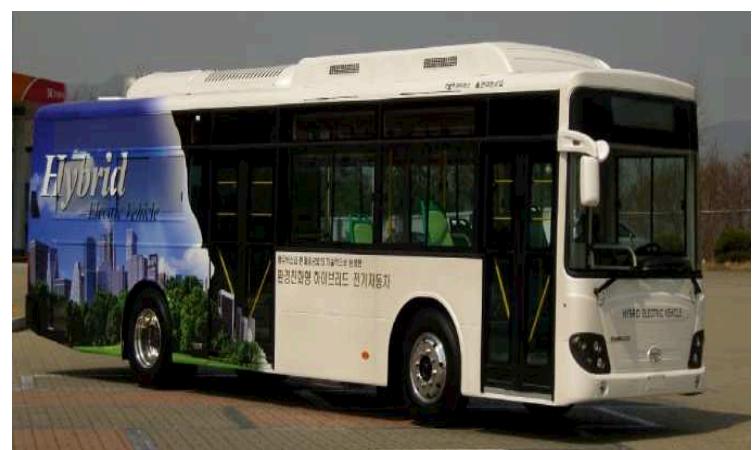

Figure 2: Photograph of BC211M Hybrid Bus

\subsection{System specifications}

Specification of the developed vehicle is shown in Table 2. The details are the 322-HP of the propulsion motor and $\mathrm{MCU}, 60 \mathrm{~kW}$ induction generator and GCU, 3.9-liter 4-cylinder with $110 \mathrm{~kW}$ capacity of diesel engine for electric power generation, 6kW-capacity on-board recharger, auxiliary system of $10 \mathrm{~kW}$ capacity and $2.8 \mathrm{~kW}$ level DC to DC Converter. The developed hybrid bus is the BC211M model of Daewoo Bus Corp. in low floor type with 50-passenger including the driver, and it has the 25-seat for the intra-city bus. Figure 2 shows the photo of the SHEB developed as BC211M.

Table 2: Specifications of the SHEB

\begin{tabular}{|c|c|c|}
\hline \multicolumn{2}{|c|}{ Vehicle Model } & $\mathrm{BC} 211 \mathrm{M}(\mathrm{DWBC})$ \\
\hline \multicolumn{2}{|c|}{ Max Speed } & $102 \mathrm{~km} / \mathrm{h}$ \\
\hline \multicolumn{2}{|c|}{ Overall Length } & $11,000 \mathrm{~mm}$ \\
\hline \multicolumn{2}{|c|}{ Overall Width } & $2,490 \mathrm{~mm}$ \\
\hline \multicolumn{2}{|c|}{ Overall Height } & $3,235 \mathrm{~mm}$ \\
\hline \multicolumn{2}{|c|}{ Wheel Base } & $5,400 \mathrm{~mm}$ \\
\hline \multicolumn{2}{|c|}{ Gross Vehicle Weight } & $15,500 \mathrm{~kg}$ \\
\hline \multicolumn{2}{|c|}{ Payload (Approximate) } & $3,500 \mathrm{~kg}$ \\
\hline \multicolumn{2}{|c|}{ Seats(passengers) } & $1+25(50)$ \\
\hline \multicolumn{2}{|c|}{ Wheel } & $8.25 \times 22.5$ \\
\hline \multicolumn{2}{|c|}{ Tires } & 11R22.5-16PR \\
\hline \multicolumn{2}{|c|}{ Gear Ratio w/o differential } & 2.93 \\
\hline \multicolumn{2}{|c|}{ Air Conditioning } & Yes \\
\hline \multicolumn{2}{|c|}{ Power Steering } & $\begin{array}{c}\text { Electrically-Driven } \\
\text { Hydraulic power assist }\end{array}$ \\
\hline \multicolumn{2}{|c|}{ Brake System } & Electric Vacuum Pump \\
\hline \multicolumn{2}{|c|}{ Low Voltage Power Supply } & $2.8 \mathrm{~kW} \mathrm{dc} / \mathrm{dc}$ \\
\hline \multicolumn{2}{|c|}{ On Board Charger } & 6kW Charger \\
\hline \multicolumn{2}{|c|}{ Electric Motor } & $322 \mathrm{hp}$ \\
\hline \multicolumn{2}{|c|}{ Motor Control Unit } & $240 \mathrm{~kW}$ \\
\hline \multicolumn{2}{|c|}{ Generator(GENSET) } & $60 \mathrm{~kW}$ \\
\hline \multicolumn{2}{|c|}{ Auxiliary System(AC/PS) } & $10 \mathrm{~kW}$ \\
\hline \multirow{4}{*}{$\begin{array}{l}\text { Engine } \\
\text { for } \\
\text { GENSET }\end{array}$} & Gloss Power & $110 \mathrm{~kW}$ \\
\hline & No. of cylinder & 4 in-line \\
\hline & Fuel & Diesel \\
\hline & Displacement & $3,900 \mathrm{cc}$ \\
\hline
\end{tabular}




\subsection{Component layout}

As described in the system configuration, main part of the hybrid is divided into five units. These units are propulsion motor with the MCU, generator with GCU, electric-driven auxiliary system, battery and Battery Management System (BMS) and monitoring system. In addition, the cooling system for the propulsion motor, GENSET, MCU, and GCU is designed separately from the existing engine cooling system. Separate cooling and heating equipment requires substantial amount of power so that the existing product is used without modification. Figure 3 shows component layout of the SHEB.

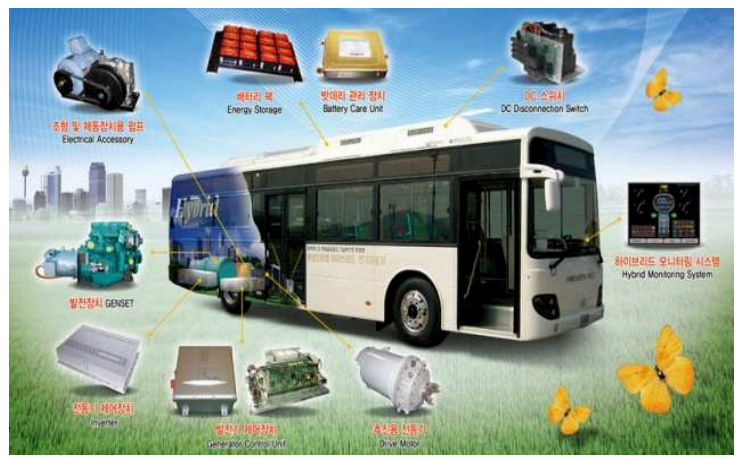

Figure 3: Component Layout of the SHEB

\subsection{Electric drive system}

The maximum output of the propulsion motor is $322 \mathrm{HP}$ as in the output capacity of 11 liter engine for existing diesel bus (ICEB), and the continuous rated output power is $161 \mathrm{hp}$. The peak power of the propulsion motor for the hybrid vehicle is two times or more continuous output power, and the express drive is possible not by using the transmission but driving only with the one-step reduction gear for the entire driving territory, and the propulsion motor is controlled by the voltage source PWM vector control inverter. In addition, in reducing the speed of coming down on downhill, the mechanical energy is recovered to obtain the regenerative braking and the generated power is recharged into the battery.

\subsection{Monitoring system}

The monitoring system of the SHEB is integrated into one for the existing ICE vehicle meter cluster, and it monitors a variety of information on devices related to the hybrid power trains in real time. It also has the touch panel for the breakdown diagnosis. The indication mark is classified as the part for each hybrid and information on existing vehicle system. The indicated screen is divided into five parts, and it has the initial screen marked when the vehicle is started and the main screen that displays various meters thereto. And on the lower part of each screen, there is an icon to move to the screen for each device below each screen. All screens of indicated device receive the information in CAN communication from each device to use the 32-bit DSP and mark it to the calculated value. [2]

\subsubsection{Main screen}

The main screen is indicated for the normal operation condition for air pressure of the vehicle, fuel meter, engine oil pressure, various telltale lamps, recharging condition of battery for SOC, and vehicle speed of the hybrid system.

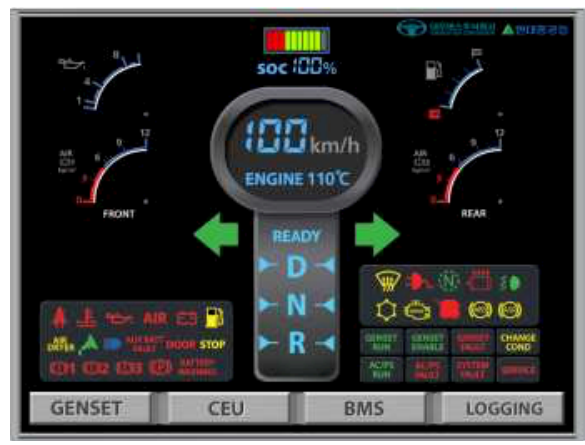

Figure 4: Main Screen of the Touch Panel

\subsubsection{CEU screen}

On the main screen, when the CEU (Control Electronics Unit) icon is touched, the MCU displays operation condition for the charger system for battery voltage, current, output power, motor and drive device for temperature.

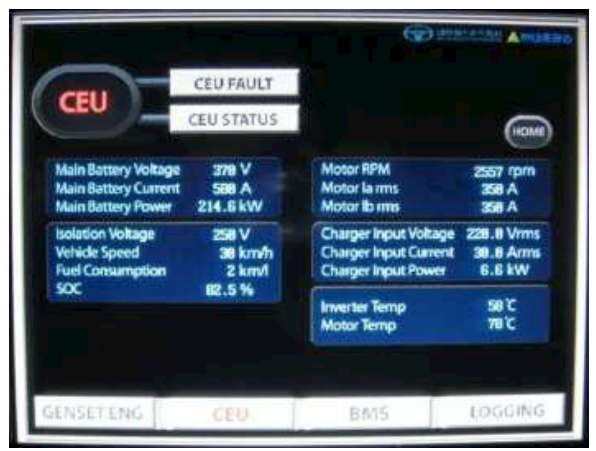

Figure 5: Screen for CEU Module

\subsubsection{GENSET screen}

On the GENSET screen, it shows the output of the GENSET, voltage, current, engine speed, cooling water temperature of GCU and generator for the GENSET. 


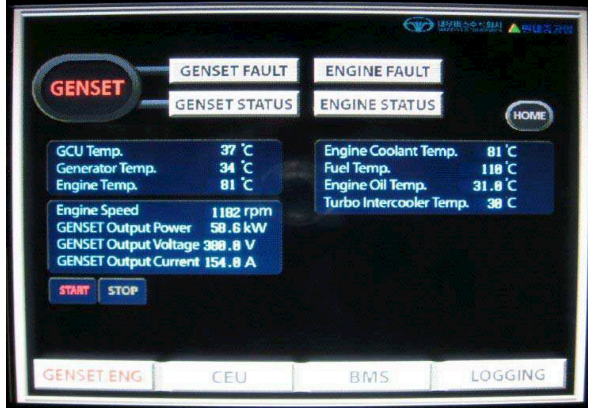

Figure 6: Screen for GENSET Module

\subsubsection{BMS screen}

Battery Management System (BMS) is the battery management device that displays each battery module with voltage, temperature, SOC, output, average, maximum and minimum voltage, and current. BMS controls the GENSET depending on SOC and the power demand for load condition of the SHEB.

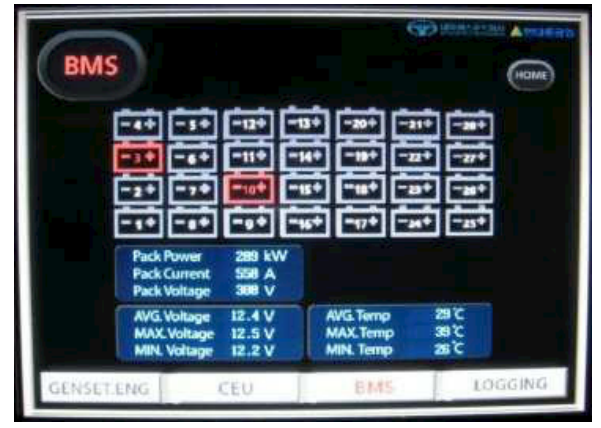

Figure 7: Screen for BMS Module

\subsection{GENSET}

The GENSET in heavy duty hybrid electric vehicle like the SHEV has used about half of the motor capacity, but according to the thesis of Hori [4], under EVS19, he turns out there has been a case of developing the system that used less than half output capacity for Permanent Magnet Synchronous Generator (PMSG) and high power density lithium ion battery. However, in this study, the GENSET that combined the 3.9liter small engine by designing induction generator of $93 \%$ for high efficiency and $60 \mathrm{~kW}$ output capability is used in consideration of the system price. Figure 8 shows the system architecture of the GENSET. Figure 9 is photograph of the GENSET. The GENSET in general for the SHEV has been controlled by ON or OFF method with the maximum output in accordance with the battery SOC and the power required for the vehicle loading. [5]

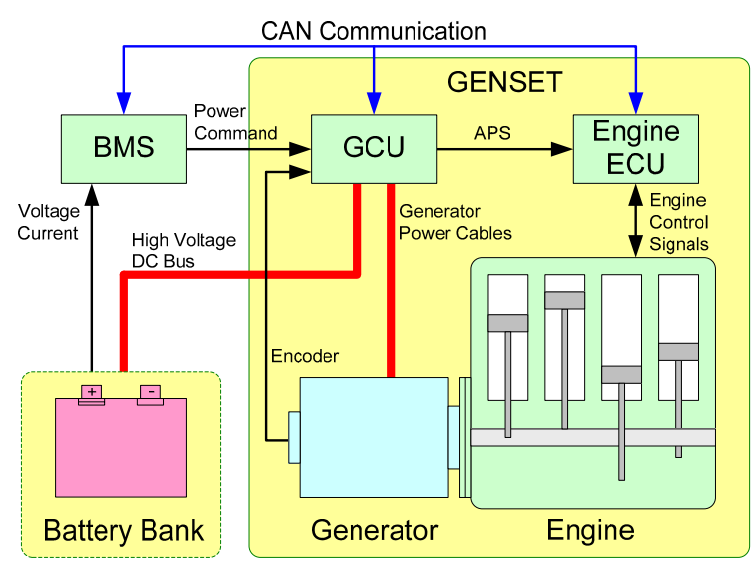

Figure 8: System Architecture of GENSET

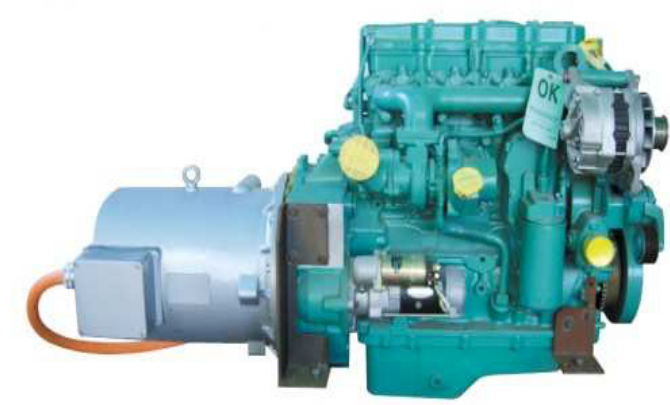

Figure 9: Photograph of GENSET

\subsubsection{Control Strategy}

The target of this control strategy is to meet the power demand commanded by the driver and, at the same time, maintain the SOC of the battery within preset range in all test driving areas. The engine can be controlled at any operating point on its speed-torque plane. The engine should be controlled in its optimal operation region, where fuel consumption and emissions of the engine are minimized. Currently, two typical control strategies are introduced: (1) maximum SOC of peaking power source (Max. SOC-of-PPS) and (2) engine turn- and turn-off (Engine-On-Off) control strategy. [5] The proposed control strategy is combined and modified strategy (1) and (2) to maintain the SOC of the battery within preset range in BUSAN City driving test. Figure 10 displays the control logic of the GENSET to maintain the battery SOC within certain range. When the SOC of the battery reaches its preset top line, the GENSET is turned off and the SOC reaches bottom line, the GENSET is turned on. Figure 11 shows engine on-off strategy. In this paper, variable output control method was used to implement the road driving test. In Figure 11 and Figure 12, the horizontal axis is time and vertical axis indicates percentage of SOC and output power 
of the GENSET respectively. Figure 10 shows the operation method of the GENSET depending on the battery SOC and the power required for the vehicle loading. The horizontal axis of Figure $10, \mathrm{X} 1, \mathrm{X} 2, \mathrm{X} 3$ and $\mathrm{X} 4$ indicates percentage of the SOC respectively and vertical axis $\mathrm{Y} 1, \mathrm{Y} 2$ is the GENSET output power. In the case of Figure 11 , when $\mathrm{X} 1$ and $\mathrm{X} 3$ are for the SOC $65 \%$, and $\mathrm{X} 2$ and $\mathrm{X} 4$ for SOC $70 \%$, the control status indicating GENSET ON for $\mathrm{Y} 2$ of $60 \mathrm{~kW}$ and OFF for the SOC $70 \%$ is shown in Figure 11.

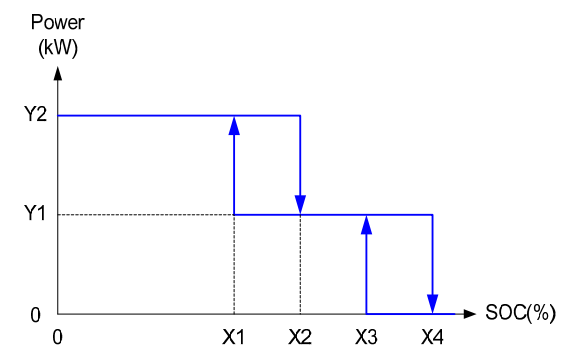

Figure 10: GENSET control logic

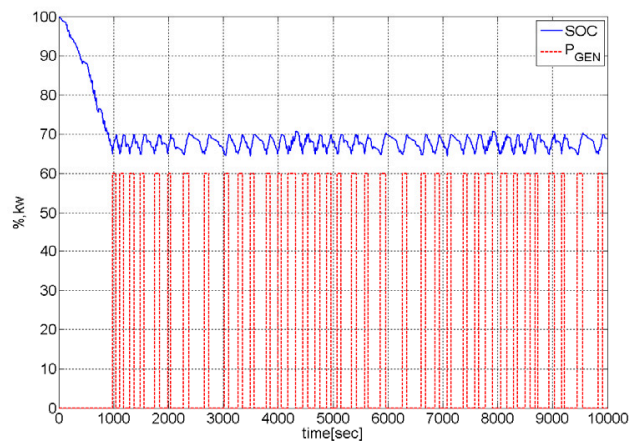

Figure 11: Engine On-Off control

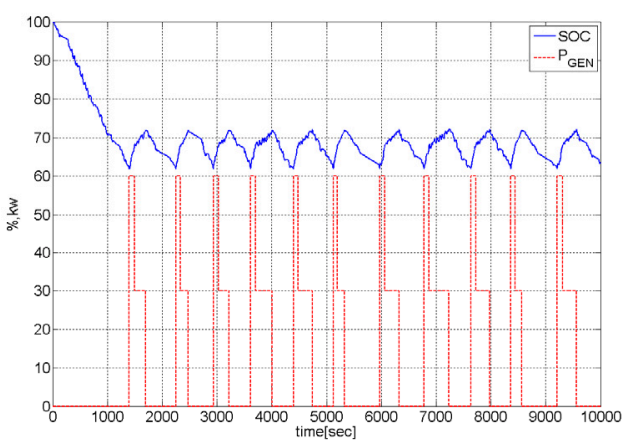

Figure 12 Variable Output Control

Figure 12 is illustrates the operation method of variable output control of the GENSET. When $\mathrm{X} 1$ and $\mathrm{X} 3$ are for the SOC $62 \%$ and $\mathrm{X} 4$ for SOC $72 \%, \mathrm{X} 2$ is for SOC $67 \%$ the control status indicating GENSET ON for Y2 of $60 \mathrm{~kW}$ and come down for $\mathrm{Y} 1$ of $30 \mathrm{~kW}$ is shown in Figure 12. The optimal operation point of $X$ and $\mathrm{Y}$ was selected by the driving test. The GENSET should be operates in optimal operation region, where fuel consumption and emission of the engine are minimized.

\subsection{Auxiliary system}

The auxiliary system is designed by connecting to the electric motor with the power steering and air pressure and is controlled by the inverter. In the event operated by the inverter, it may save the energy by preventing the inrush current of the power motor with the soft operation and suspension, and the sensor of the air pressure and the hydraulic pump are controlled to minimize the power consumption.

\section{Simulation}

Modeling for the hybrid cars and each component is realized with SIMULINK. The model is configured with the MCU, GENSET, BUSAN city driving mode, battery and others. In the event that the accurate tuning is made for the various parameters, the simulation result and the actual test result were consistent. The simulation was made for the acceleration capability, drive ability of gradient, and fuel consumption on city driving mode. As a result of the simulation, it has accomplished $22.8 \%$ of the fuel economy improvement and running for the slope of $25 \%$. Table 3 displays the acceleration performance both ordinary bus (ICEB) and SHEB. As shown on Table 3, the acceleration of the SHEB would have 12.5 seconds to reach from $0 \mathrm{~km} / \mathrm{h}$ to $60 \mathrm{~km} / \mathrm{h}$, and 23.5 seconds to reach from $0 \mathrm{~km} / \mathrm{h}$ to $80 \mathrm{~km} / \mathrm{h}$ respectively. Figure 13 is the simulation result of the acceleration time of the SHEB. Compared to the ordinary bus, the SHEB shows outstanding acceleration capability in the test result and simulation. Under the actual road condition, the acceleration test up to $80 \mathrm{~km} / \mathrm{h}$ shows really excellent results. In addition, in the event that it is driven in BUSAN city driving mode, the GENSET control would maintain certain SOC on its entire area. During the simulation, it was implemented for $100 \%$ of SOC while the initial condition of the battery was fully charged. The driving mode used in simulation is provided by Daewoo Bus. Figure 15 shows the simulation result of BUSAN city driving mode. The horizontal axis of Figure 15 is time and vertical axis indicates percentage of SOC and vehicle speed. As shown in the simulation result, SOC control would maintain uniformly on its entire area. Figure 14 displays simulation result of gradability of the SHEB. Figure 16 is simulation result of high speed mode of the SHEB. 
Table 3: Acceleration Performance

\begin{tabular}{c|c|c}
\hline Speed $(\mathrm{km} / \mathrm{h})$ & ICEB $(\mathrm{sec})$ & SHEB $(\mathrm{sec})$ \\
\hline $0-60$ & 16.4 & 12.5 \\
\hline $0-80$ & 27.1 & 23.5 \\
\hline $0-100$ & 45.6 & 42 \\
\hline
\end{tabular}

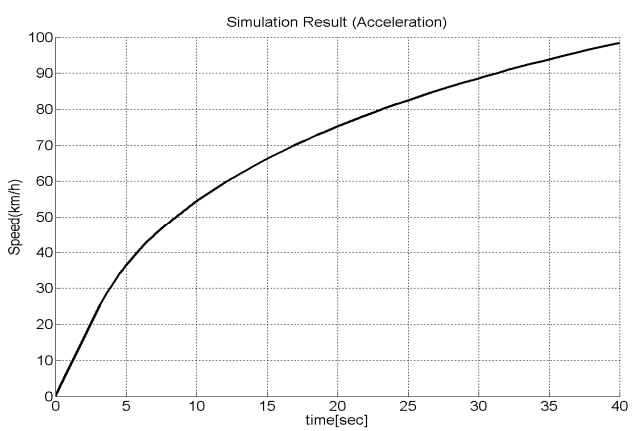

Figure 13: Acceleration of the SHEB

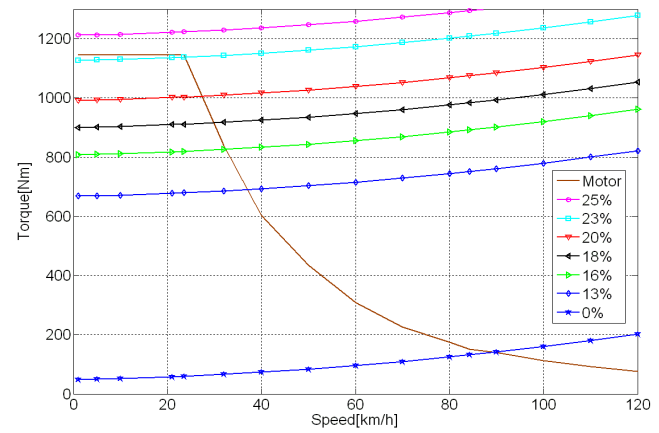

Figure 14: Gradeability vs. vehicle speed

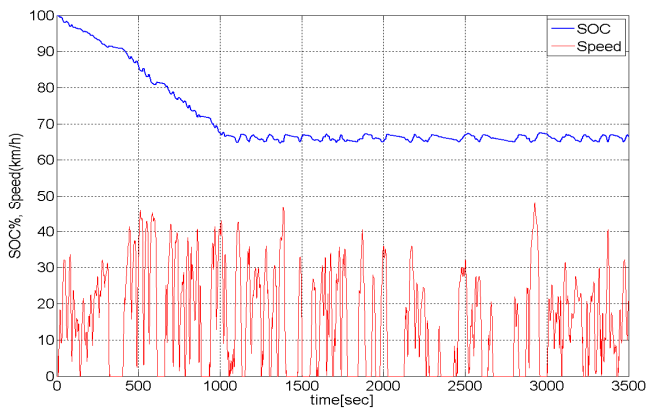

Figure 15: BUSAN City Mode

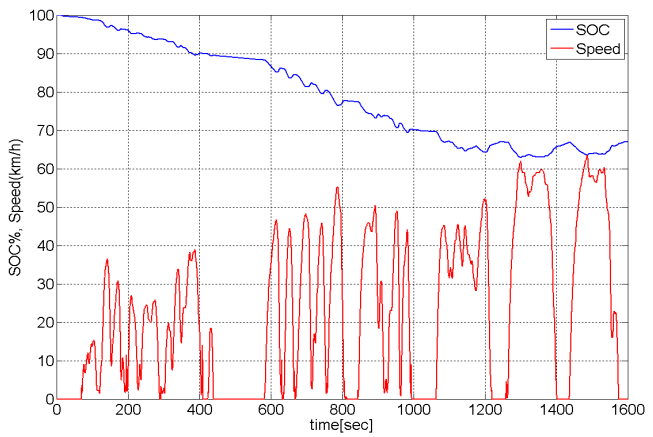

Figure 16: High speed mode

\section{Test result and discussion}

\subsection{Test result}

The driving test and acceleration test were implemented while $100 \%$ load (payload is $3,500 \mathrm{~kg}$ ) was fully made. Figure 17 shows the inside of the vehicle with the load of $3,500 \mathrm{~kg}$ on the vehicle for the road running test. In the Figure 17, the black color is the sand bag of $10 \mathrm{~kg}$ of weight that was used for the load. Figure 18 is the map of BUSAN city, and the driving road for testing is marked with bold and dark line. The driving mode used in the test is used for ordinary bus as the standard model used to evaluate the vehicle fuel economy test and it includes the running road exclusively for the bus. The result of acceleration performance in Figure 19 was measured in the road of an exclusive bus driving lane. Figure 20 displays the SOC of the battery measured during running and the inner-city driving mode. The horizontal axis of Figure 20 is time and vertical axis indicates percentage of SOC and vehicle speed. The red line is BUSAN city driving mode. As shown in the test result, the SOC was consistently maintained within $10 \%$ in all test driving areas. Table 4 is performance comparison of the simulation and test result of the SHEB. The result of simulation was almost consistent with test result. On the road, as a result of acceleration up to $60 \mathrm{~km} / \mathrm{h}$, it was similar to the simulation result with 13 seconds, which is better than the case of ICE vehicle. Figure 21 is test result of high speed mode of the SHEB. The SOC was consistently maintained within $10 \%$ range. The drive ability of grade was carried out in hills, and the digital slope meter is used to have the consistent simulation result. The drive ability of grade was $23 \%$.

\subsection{Discussion}

The SHEB that used the one-step reduction gear without the transmission had no problem in running on even road. With the minimized design of the battery and GENSET, it has certain limits in running uphill or running on drastic sloped road. The SHEB may guaranty the highest economic feasibility to have the design made in accordance with the service area and road condition. All tests had to be undertaken in actual road except measurement of exhaust gas per each running distance. Its measurement and review have to be made later. There is a need of changing the cooling and heating device into electric motor device, and 
the design of the power system at this time has to be reviewed again. When the bus stops in the dense commercial area, and the maximum output of the GENSET is undertaken, the SHEB makes severe noises. However, in the event that the SHEB runs slowly about less than $10 \mathrm{~km} / \mathrm{h}$ or stops at the bus station, the noise can be reduced by the low output or stopping the GENSET.

As a result of the test, it was also found that there was no significant difference in maintaining SOC within the acceptable range during driving. It was also showing that fuel economy depending on the road condition, traffic and driving habit of a driver. In the event that the driving is made for high speed at the exclusive bus lane, the fuel economy was shown to be lower than the average value.

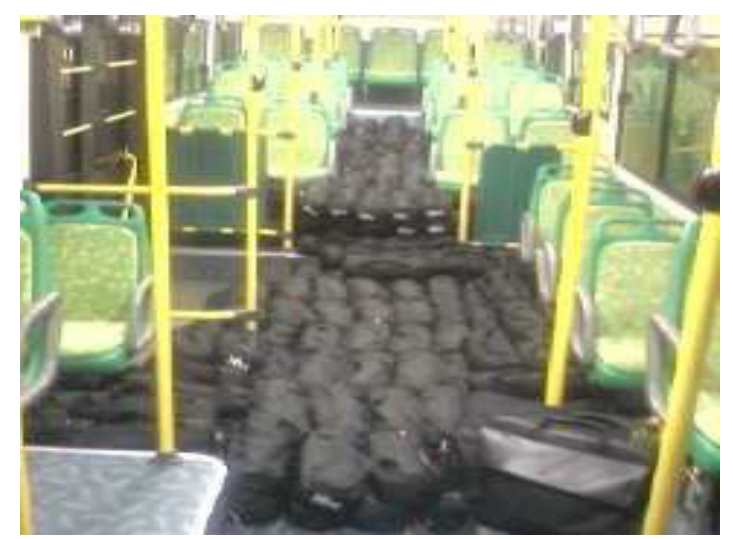

Figure 17: Inner View of vehicle with the Load

Table 4: Performance comparison

\begin{tabular}{c|c|c}
\hline & Simulation & Test Result \\
\hline $\begin{array}{c}\text { Acceleration(sec) } \\
(0-60 \mathrm{~km} / \mathrm{h})\end{array}$ & 12.5 & 13 \\
\hline $\begin{array}{c}\text { Fuel consumption } \\
(\mathrm{km} / \text { liter})\end{array}$ & 2.58 & 2.56 \\
\hline Fuel efficiency (\%) & 22.8 & 22 \\
\hline Gradeability (\%) & 25 & 23 \\
\hline
\end{tabular}

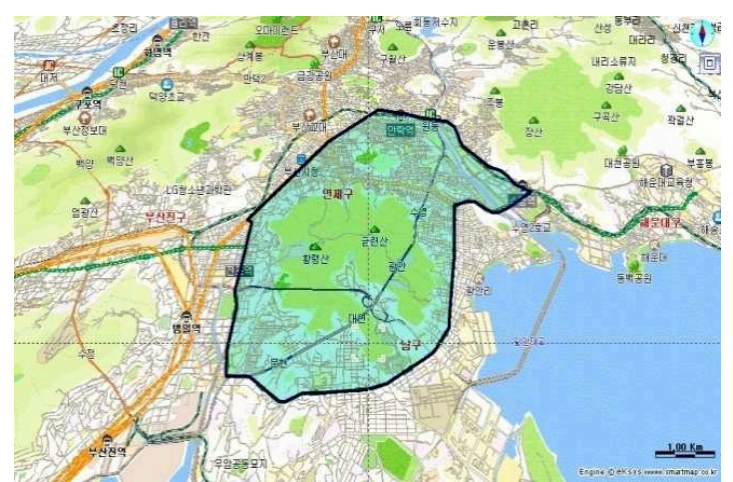

Figure 18: Road map of BUSAN City Test Route

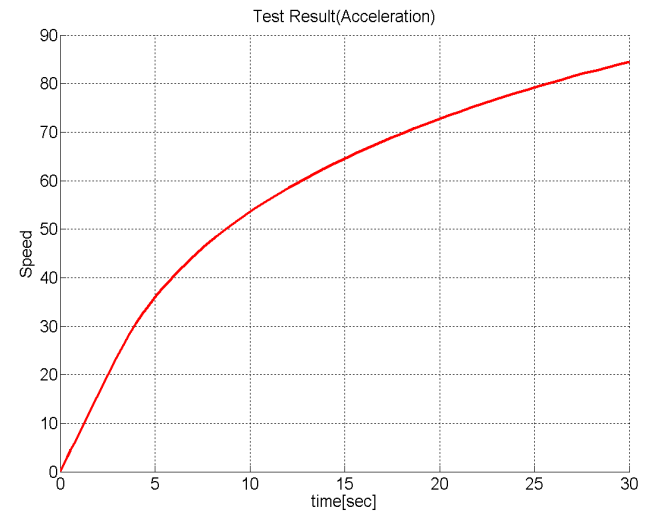

Figure 19: Test Result of Acceleration

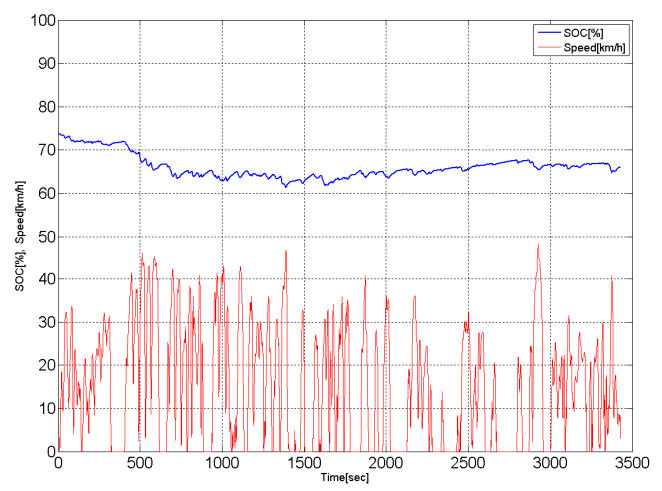

Figure 20: Test Result of BUSAN City Mode

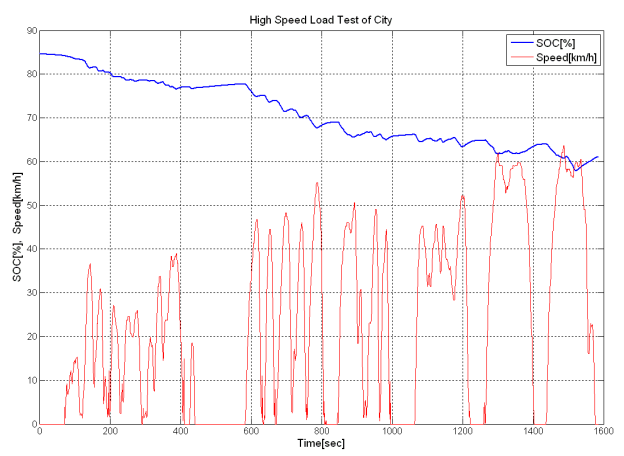

Figure 21: Test result of high speed mode

\section{Conclusion}

A prototype Series Hybrid Electric Bus has been developed to evaluate vehicle performance together with fuel economy as a part of feasibility study on hybrid bus operation. The test and simulation of the SHEB in an exclusive busdriving lane has been performed including the measurement of fuel consumption. It was found that the developed SHEB was met the target fuel 
economy with affordable system configuration, which was advantageous to commercialization of the system compared to other SHEB.

\section{Acknowledgments}

This work was performed by Hyundai Heavy Industries Company (HHI) and Daewoo Bus Corporation through the joint development. The GENSET used in this work was technically supported by Hyundai Enova Innovation Technology Centre (HEITC). The monitoring system was developed by university of Ulsan with financial support of HHI for the IndustriesUniversity R\&D consortium program.

\section{References}

[1] Stefano Barsali et. al., Techniques to Control the Electricity Generation in a Series Hybrid Electrical Vehicle, IEEE. Transactions on energy conversion., VOL. 17. No. 2, June 2002.

[2] T.W. Chun, U.D. Choi, et. al., Development of Monitoring System for Series HEV Bus with Touch Panel, EPE-PEMC 2008, pp. 1444-1488.

[3] U.D. Choi, et, al., Development of the Power Generator for Series Hybrid Electric Vehicle. IFOST 2006, pp. 447-450.

[4] Yusuke Hori, et, al., A Hybrid Electric Drive System For Low-Floor City BUS EVS-19, 2002.

[5] Mehrdad Ehsani et. Al., Modern Electric, Hybrid Electric, and Fuel Cell Vehicles, CRC press, 2005. pp. 239-276.

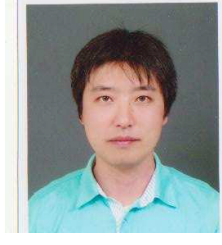

Se-Jin Oh was born in Busan, Korea, in 1973. He was received his B.S., M.S. degrees in Measurement and Mechanical Control from Busan National University, Busan in Korea. $\mathrm{He}$ was involved in the development of the Series Hybrid Electric Bus. He is working as engineer of Proto build and Test team of Daewoo Bus Corporation.

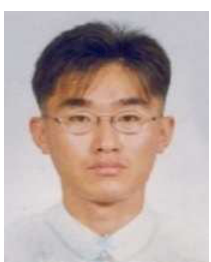

Chang-Hee Lee was born in in Seoul, Korea in 1973. He was received his B.S. degrees in Electronic Engineering from University of Danguk, Seoul in Korea. He is working as engineer of Hyundai Heavy Industries Co., Ltd.

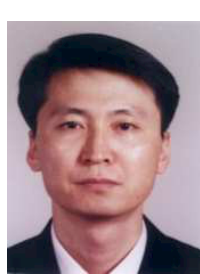

Se-Hyun Lee was born in Boeun, Chungbuk, Korea, in $1960 \mathrm{He}$ received his B.S., M.S. degrees in Electrical Engineering from University of Cungbuk National University, Ceongju in Korea. He was involved in the design and development of the high voltage Inverter for high power. $\mathrm{He}$ is currently the head of a department of power conversion research of Electro-Mechanical Research Institute of Hyundai Heavy Industries Co., Ltd.

\section{Authors}

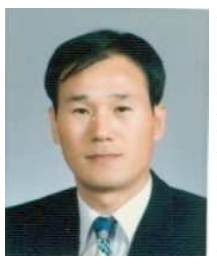

Uk-Don Choi was born in Daegu, Korea, in 1955. He received his B.S., M.S. and Ph.D. degrees in Electrical Engineering from University of Yeung nam, Gyeongsan in Korea. He was involved in the joint development of the Series Hybrid Electric Bus with Daewoo Bus Corporation. His main research interests in power electronics, control of $\mathrm{HEV} / \mathrm{EV}$ systems. He is principal researcher of ElectroMechanical Research Institute of Hyundai Heavy Industries Co., Ltd. 